\title{
Perseverance is the Key
}

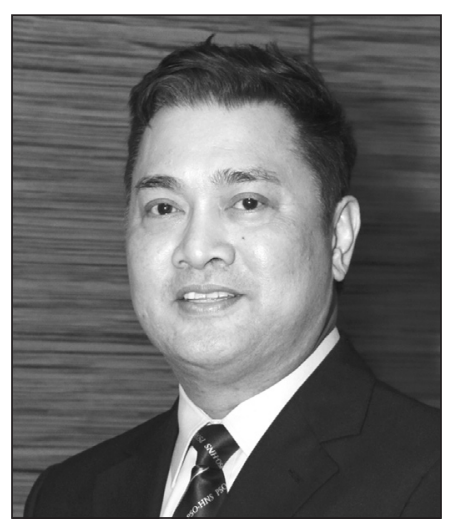

\section{Greetings to all ENT Fellows!}

When I became a member of the Board of Trustees during the Presidency of Dr. Cesar Anthony Yabut in 2012, I surmised how concerned and dedicated the Board was in supporting and funding researches of fellows-- whether they were descriptive, analytical, surgical innovations and instrumentations -- through the PSO-HNS research committee.

Amendments to the research paper contest guidelines were made to give way to the advent of information technology in synchronization with the electronic journal management system of the Philippine Journal of Otolaryngology Head and Neck Surgery (PJOHNS). Online review and corrections were implemented to maximize time and efforts of the judges and the authors. This was given emphasis during the administration of Dr. Wilfredo Batol in 2013.

Well, these are all done for academic excellence. Under Dr. Howard Enriquez' administration in 2014, research still remained one of the priorities of PSO-HNS. Each and every paper submitted passed through the eye of the needle of the editorial board of PJOHNS. It may be a lot of hard work and effort for the researchers, judges and editors but it is worth the hard work.

PERSEVERANCE is the key! Just choose a"worth-knowing" topic and write a "worth-publishing" paper. If it is rejected, just try again. Be patient with the corrections and revisions-- in the end, the fruit of your labor is a sweet success.

An ORL-HNS specialist should be equipped with this trait to really cope with the ever changing needs of our society whether it is surgically or research oriented as evidenced by our very own PJOHNS.

It is with great pride and honor that I render a message in our prestigious journal. I would like to take this opportunity to express my sincere gratitude and congratulations to my colleague, Dr. Joey Lapena, and the same is true for the editorial staff and members for their never ending dedication and hard work in making a journal that is equally competitive and accepted in the 21st Century.

Mabuhay!

ARMANDO M. CHIONG, JR., MD

President

Philippine Society of Otolaryngology-Head and Neck Surgery 